\title{
Correction to: Selective Synthesis of Cyclohexanol Intermediates from Lignin-Based Phenolics and Diaryl Ethers using Hydrogen over Supported Metal Catalysts: A Critical Review
}

\author{
Sreedhar Gundekari ${ }^{1}$ · Sanjib Kumar Karmee ${ }^{1}$ (D)
}

Accepted: 11 November 2020 / Published online: 24 November 2020

○) Springer Science+Business Media, LLC, part of Springer Nature 2020

\section{Correction to: Catalysis Surveys from Asia https://doi.org/10.1007/s10563-020-09315-3}

The authors make the following corrections in the paper:

Figures 1, 5 and 6 are taken from other papers. The relevant papers are cited in the text but the authors would like to cite these in the figures as well.

The revised captions are:

Fig. 1 Structure of lignin with monomeric units (sinapyl, coumaryl, and coniferyl) (image taken from Lee et al. Reference 9)

Fig. 5 GC-MS profile of hydrodeoxygenation or/and hydrogenation of lignin oil to cyclic alcohols using $\mathrm{Ni} /$ $\mathrm{Nb}_{2} \mathrm{O}_{5}$ catalyst in an aqueous medium under $\mathrm{H}_{2}$ (image taken from Song et al. Reference 79)
Fig. 6 Reported proposed mechanism for the hydrodeoxygenation-hydrogenation of vanillin to methylcyclohexanol using bimetallic $\mathrm{CoNi} / \mathrm{Al}_{2} \mathrm{O}_{3}$ catalyst and $\mathrm{H}_{2}$ in the presence of isopropanol medium (image taken from Liu et al. Reference 99)

The authors duly acknowledge and highly appreciate original research contributions made by esteemed Lee et al. (Ref. 9), Song et al. (Ref 79), and Liu et al. (Ref. 99). Finally, the authors apologise for any inconvenience caused. The original article has been corrected.

Publisher's Note Springer Nature remains neutral with regard to jurisdictional claims in published maps and institutional affiliations.
The original article can be found online at https://doi.org/10.1007/ s10563-020-09315-3.

Sreedhar Gundekari

thermo1@spreri.org; sreedhar.gundekari@gmail.com

Sanjib Kumar Karmee

thermo@spreri.org; sanjibkarmee@gmail.com

1 Thermo Chemical Conversion Technology Division, Sardar Patel Renewable Energy Research Institute (SPRERI), Near BVM Engineering College, Vallabh Vidyanagar, Post Box No. 2, Anand, Gujarat 388 120, India 